\title{
Effect of Exhaust Gas Recirculation on Performance and Emission Characteristics of a Diesel-Piloted Biogas Engine
}

\author{
Meshack Hawi $^{1 *}$, Robert Kiplimo ${ }^{2}$, Hiram Ndiritu ${ }^{1}$ \\ ${ }^{1}$ Department of Mechanical Engineering, JKUAT, Nairobi, Kenya \\ ${ }^{2}$ Department of Marine Engineering, JKUAT, Nairobi, Kenya \\ Email: "
}

Received 20 February 2015; accepted 14 April 2015; published 20 April 2015

Copyright (C) 2015 by authors and Scientific Research Publishing Inc.

This work is licensed under the Creative Commons Attribution International License (CC BY). http://creativecommons.org/licenses/by/4.0/

(c) $\underset{\mathrm{EY}}{\mathrm{i}}$ Open Access

\begin{abstract}
In this research, a Direct Injection Compression Ignition (DICI) engine was modified into a dualfuel engine that used biogas as the primary fuel and diesel as pilot fuel, with the focus on reduction of harmful exhaust emissions while maintaining high thermal efficiency. The effect of exhaust gas recirculation (EGR) on engine performance and emission characteristics was studied. The EGR system was developed and tested with different EGR percentages, i.e. $0 \%, 10 \%, 20 \%$ and $30 \%$. The effect of EGR on exhaust gas temperature and performance parameters like brake specific fuel consumption, brake power and brake thermal efficiency was studied. The performance and emission characteristics of the modified engine were compared with those of the conventional diesel engine. The results showed that EGR led to a decrease in specific fuel consumption and an increase in brake thermal efficiency. With increase in percent (\%) of EGR, the percentage increase in brake thermal efficiency was up to $10.3 \%$ at quarter load and up to $14.5 \%$ at full load for single fuel operation while for dual-fuel operation an increase up to $9.5 \%$ at quarter load and up to $11.2 \%$ at full load was observed. The results also showed that EGR caused a decrease in exhaust gas temperature; hence it's potential to reduce $\mathrm{NO}_{\mathrm{X}}$ emission. However, emissions of $\mathrm{HC}$ and $\mathrm{CO}$ increased slightly with EGR.
\end{abstract}

\section{Keywords}

DICI Engine, Dual-Fuel Engine, EGR, $\mathrm{NO}_{x}$

\section{Introduction}

Regulations for particulate matter (PM) and oxides of nitrogen $\left(\mathrm{NO}_{\mathrm{X}}\right)$ emissions from diesel engines have been

\footnotetext{
${ }^{*}$ Corresponding author.
}

How to cite this paper: Hawi, M., Kiplimo, R. and Ndiritu, H. (2015) Effect of Exhaust Gas Recirculation on Performance and Emission Characteristics of a Diesel-Piloted Biogas Engine. Smart Grid and Renewable Energy, 6, 49-58. 
strengthened and therefore there is need to find alternative fuels for the engines and ways of reducing harmful exhaust emissions while maintaining high thermal efficiency. The concept of using alternative gaseous fuel in diesel engines has gained worldwide attention. Increasing petroleum fuel prices and their deterioration to environment have led to the search for alternative fuels in the past several years [1]. Biogas is one such fuel, which is produced easily by anaerobic fermentation of organic material extracted from varied sources like animal wastes, vegetable wastes, wastes from households, wastes from the food and fodder industry and waste from productive livestock husbandry [2].

Diesel engines are typically characterized by low fuel consumption and very low CO emissions. However, the $\mathrm{NO}_{\mathrm{X}}$ emissions from diesel engines still remain high. Hence, in order to meet the environmental regulations, it is highly desirable to reduce the amount of $\mathrm{NO}_{\mathrm{X}}$ in the exhaust gas. Diesel engines are predominantly used in heavy duty machinery such as tractors, heavy lorries, trucks and electrical generator sets. Owing to their low fuel consumption, they have become increasingly attractive for smaller lorries and passenger cars as well. But higher $\mathrm{NO}_{\mathrm{X}}$ emissions from diesel engines remain an environmental concern. In order to reduce emission levels, some external engine features can be applied, such as EGR or after treatment systems. EGR systems have been used to reduce emissions of nitrogen oxides $\left(\mathrm{NO}_{\mathrm{X}}\right)$ from diesel engines. Depending on the engine operating conditions, these systems divert $5 \%-30 \%$ of an engine exhaust stream back to the combustion chamber [3].

In diesel engines, $\mathrm{NO}_{\mathrm{X}}$ formation is a highly temperature dependent phenomenon and takes place when the temperature in the combustion chamber exceeds $2000 \mathrm{~K}$ [4]. Therefore, in order to reduce $\mathrm{NO}_{\mathrm{X}}$ emissions in the exhaust, it is necessary to keep peak combustion temperatures under control. One simple way of reducing the $\mathrm{NO}_{\mathrm{X}}$ emission of a diesel engine is by late injection of fuel into the combustion chamber. This technique is effective but increases fuel consumption by $10 \%-15 \%$, which necessitates the use of more effective $\mathrm{NO}_{\mathrm{X}}$ reduction techniques like exhaust gas recirculation (EGR) [4]. Recirculating part of the exhaust gas helps reduce $\mathrm{NO}_{\mathrm{X}}$. When exhaust gas is recirculated, it is important to investigate the effect on engine performance characteristics as well.

Exhaust gas consists of $\mathrm{CO}_{2}, \mathrm{~N}_{2}$ and water vapor mainly. When a part of this exhaust gas is recirculated to the cylinder, it acts as diluent to the combusting mixture. This also reduces the $\mathrm{O}_{2}$ concentration in the combustion chamber. The specific heat of the EGR is much higher than fresh air; hence EGR increases the heat capacity (specific heat) of the intake charge, thus decreasing the temperature rise for the same heat release in the combustion chamber [4]. Diesel engines can be modified to operate with gaseous fuel in dual-fuel mode. Dual-fuel engines at part load inevitably suffer from lower thermal efficiency and higher emission of carbon monoxide and unburned fuel. Hosseinzadeh et al. [5] used a quasi-two-zone combustion model developed for studying the second-law analysis of a dual-fuel (diesel-gas) engine operating under part load conditions. They made an attempt to investigate the combustion phenomenon from second-law point of view at part load and use exhaust gas recirculation (EGR) to improve the aforementioned problems. Therefore, the availability analysis was applied to the engine from inlet valve closing (IVC) until exhaust valve opening (EVO). Various availability components were identified and calculated separately with crank position. The different cases of EGR (chemical, radical and thermal cases) were then applied to the availability analysis in dual-fuel engines at part loads. They found that the chemical case of EGR had negative effect and in this case the unburned chemical availability was increased and the work availability decreased in comparison with baseline engine (without EGR). The thermal and radical cases had positive effects on the availability terms especially on the unburned chemical availability and work availability. The results showed that second-law efficiency was increased by using low amount of radical and thermal cases of EGR.

Their results showed that radical, thermal and combined cases of EGR had positive effects on availability terms. With employment of these cases of EGR, the combustion process improved due to enhancement of the oxidation process in lean mixtures. Also in these cases, the presence of very active radicals and a higher intake charge temperature could promote the combustion process and therefore reduced the chemical availability of unburned fuel in the exhaust gases. Their results also indicated that the dual-fuel engine can obtain maximum work availability, minimum destruction availability and minimum chemical availability of unburned fuel when $2 \%$ of thermal or combined cases of EGR was introduced to the dual-fuel engine under part load operating conditions.

\section{Description of the Experimental Procedure}

The engine typically used for this study is a single cylinder four stroke Direct Injection (DI) diesel engine. It is 
water cooled, naturally aspirated constant speed compression ignition engine whose major specifications are shown in Table 1. The engine was coupled to a hydraulic dynamometer through which load was applied by increasing the water supply to rotor blades through a centrifugal pump. The engine was tested at $0,25,50,75$ and 100 percent brake load conditions. The engine had capability to run either on pure diesel or dual-fuel mode. The engine was modified to run on biogas by introducing it in the intake manifold pipe via a mixing device. The biogas flow rate was kept fixed for a given speed and load, and a variable pilot injection quantity controlled by a manual regulator fixed at the injection pump. The experimental apparatus is shown in Figure 1.

Biogas generated from water hyacinth, in a digester was collected in a flexible bag $\left(3 \mathrm{~m}^{3}\right)$ and used for tests in the laboratory (engine room). The properties of the gas are shown in Table 2. The gas was then supplied to the engine through a biogas transfer pump. The volume flow rate of the gas was controlled by a valve and measured using a gas flow meter before being admitted into the intake manifold. For every test, the initial and final meter reading was recorded as well as time taken to consume the gas. The volume of gas consumed by the engine was calculated by subtracting the initial from the final meter reading. Mass flow rate was calculated using volume of gas consumed, density of the gas and the time. The power output of the engine was measured using a Fuchino SF-3.5 hydraulic dynamometer by recording the dial reading (in kgf) and then converting into brake power (hose power) by applying Equation (1). The EGR circuit consisted of a stainless steel pipe and stainless steel butterfly valves fitted to control the quantity of exhaust gas being re-circulated. The volume of pilot (liquid) fuel consumed was measured by a calibrated glass tube (burette) by measuring the time required for the consumption of $10 \mathrm{ml}$ of fuel. During exhaust gas recirculation, the EGR control valves were used to regulate the amount of exhaust allowed back into the combustion chamber. During the experiments, dynamometer reading (load), engine speed, fuel consumption and exhaust gas temperature were recorded. Exhaust gases were analyzed on line by Horiba MEXA-544GF emission analyzer in which $\mathrm{HC}, \mathrm{CO}$ and $\mathrm{CO}_{2}$ were measured. A portable Laser Type digital tachometer-RS 445-9557 was used to measure the engine speed at all operating conditions. Thermocouples were fixed at the exhaust manifold and at engine coolant inlet and outlet to the engine to measure the temperature of exhaust gas, temperature of cooling water at entry to the engine and temperature of cooling water at exit from the engine respectively.

Table 1. Engine specifications.

\begin{tabular}{ccc}
\hline S/No. & Specification & Value \\
1 & Number of cylinders & 1 \\
2 & Number of strokes & 4 \\
4 & Rated power (kW) & 1500 \\
5 & Speed (rpm) & $16.5: 1$ \\
6 & Compression ratio & 251 \\
7 & Fuel consumption (g/kWh ) & 200 \\
8 & Injection pressure (bar) & 23 \\
10 & Injection timing ( $\mathrm{btdc})$ & 950 \\
& Cylinder capacity (cc) & Direct injection
\end{tabular}

Table 2. Properties of biogas.

\begin{tabular}{ccc}
\hline S/No. & Quantity & Value \\
\hline 1 & Methane (\%) & $21-29$ \\
2 & Carbon dioxide (\%) & $17-19$ \\
3 & Nitrogen (\%) & 1.22 \\
4 & Density $\left(\mathrm{kg} / \mathrm{m}^{3}\right)$ & 19,100 \\
6 & LHV $(\mathrm{kJ} / \mathrm{kg})$ & 130 \\
7 & Octane number & $632-813$ \\
\end{tabular}




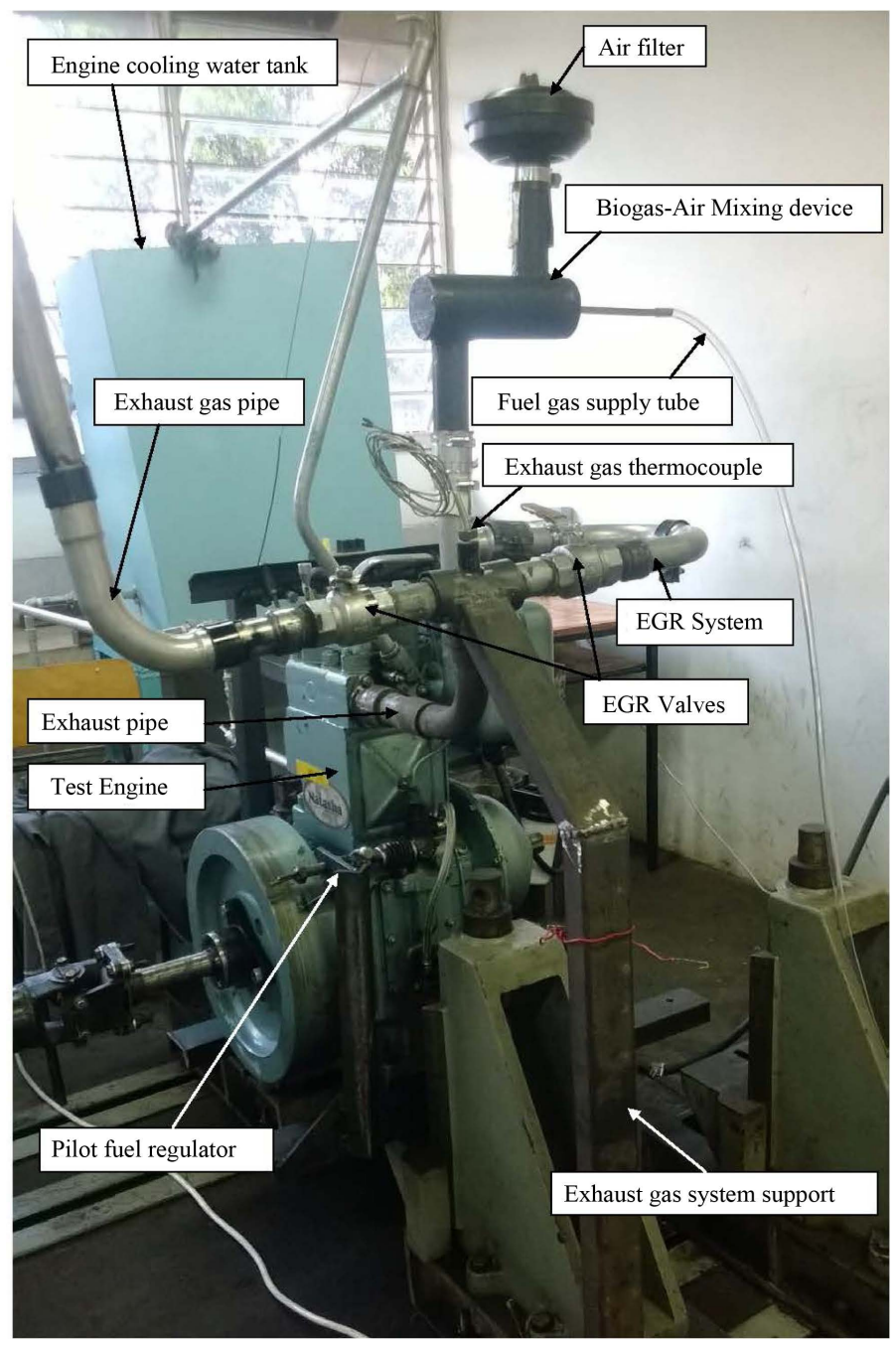

Figure 1. Photograph of the experimental set up.

\section{Performance Analysis of the Engine}

The following equations were used in analysis of the collected data.

Engine brake horse power:

$$
P . S=\frac{W \times N}{1000}
$$

where $P . S=$ brake horse power, $W=$ torque indication in $\mathrm{kg}, N=$ revolution per minute.

Specific fuel consumption:

$$
S F C=\frac{\dot{m}_{f}}{\dot{W}}
$$

where $S F C=$ specific fuel consumption, $\dot{m}_{f}=$ rate of fuel flow into engine and $W=$ engine power.

Brake specific fuel consumption:

$$
B S F C=\frac{\dot{m}_{f}}{\dot{W}_{b}}
$$

where $B S F C=$ brake specific fuel consumption, $\dot{m}_{f}=$ rate of fuel flow into engine and $W_{b}=$ brake engine power.

Thermal efficiency: 


$$
\eta_{t h}=\frac{\dot{W}}{\dot{m}_{f} \times C V}
$$

where $\eta_{t h}=$ thermal efficiency, $W=$ engine power, $\dot{m}_{f}=$ rate of fuel flow into engine and $C V=$ calorific value of fuel.

\section{Brake thermal efficiency:}

$$
\eta_{b t h}=\frac{\dot{W}_{b}}{\dot{m}_{f} \times C V}
$$

where $\eta_{b t h}=$ brake thermal efficiency, $W_{b}=$ brake power, $\dot{m}_{f}=$ rate of fuel flow into engine and $C V=$ calorific value of fuel.

Brake thermal efficiency of engine in dual-fuel mode:

$$
\eta_{b t h}=\frac{\dot{W}_{b}}{\dot{m}_{f d} \times C V_{d}+\dot{m}_{f g} \times C V_{g}}
$$

where BTE $=\eta_{b t h}=$ brake thermal efficiency, $W_{b}=$ brake power, $\dot{m}_{f d}=$ rate of flow of diesel fuel into engine, $\dot{m}_{f g}=$ rate of flow of biogas fuel into engine, $C V_{d}=$ calorific value of diesel fuel and $C V_{g}=$ calorific value of biogas fuel.

Diesel Substitution:

$$
d s=\frac{D_{d}-D_{d g}}{D_{d}} \times 100
$$

where $d s=$ diesel substitution, per cent, $D_{d}=$ diesel consumption by the engine on single fuel mode in $\mathrm{kg} / \mathrm{h}$, $D_{d g}=$ diesel consumption by the engine on dual-fuel mode in $\mathrm{kg} / \mathrm{h}$.

Percentage of exhaust gas recirculation [3]:

$$
\% \text { EGR }=\frac{\text { Volume of EGR }}{\text { Total Intake Charge to the Cylinder }} \times 100
$$

\section{Results and Discussions}

\subsection{Engine Performance}

\subsubsection{Brake Specific Fuel Consumption (BSFC)}

Figure 2 shows the variation of BSFC with engine load for various percentages of EGR; by varying the percentage of exhaust gas which is recirculated under $0 \%, 25 \%, 50 \%, 75 \%$ and $100 \%$ load. It was found that brake specific fuel consumption decreased with increase in EGR and reached a minimum value at about $20 \%$ EGR and then increased slightly up to 30\% EGR from 50\% load to full load. The decrease in BSFC with EGR is due to increase in intake charge temperature which increases the rate of combustion of the fuel, hence causing a decrease in BSFC.

\subsubsection{Brake Power}

Figure 3 shows the variation of engine power output with load. It shows that EGR has no significant effect on the power output of the engine up to 30\% EGR. This is because the recirculated gases do not displace too much of the air required for combustion which could cause a decrease in power output.

\subsubsection{Brake Thermal Efficiency}

From Figure 4, showing variation of BTE with engine load, the brake thermal efficiency increases with increase in engine load for all operating modes. The BTE increases also with EGR up to about 20\% EGR and then starts to fall. The reason for increase in BTE with EGR is due to re-burning of HC that enters combustion chamber with the recirculation of exhaust gases and also EGR increases intake charge temperature which increases the rate of combustion [6]. Recirculation of too much exhaust gases, however, displaces much of the necessary air for combustion, hence leading to decrease in thermal efficiency. 


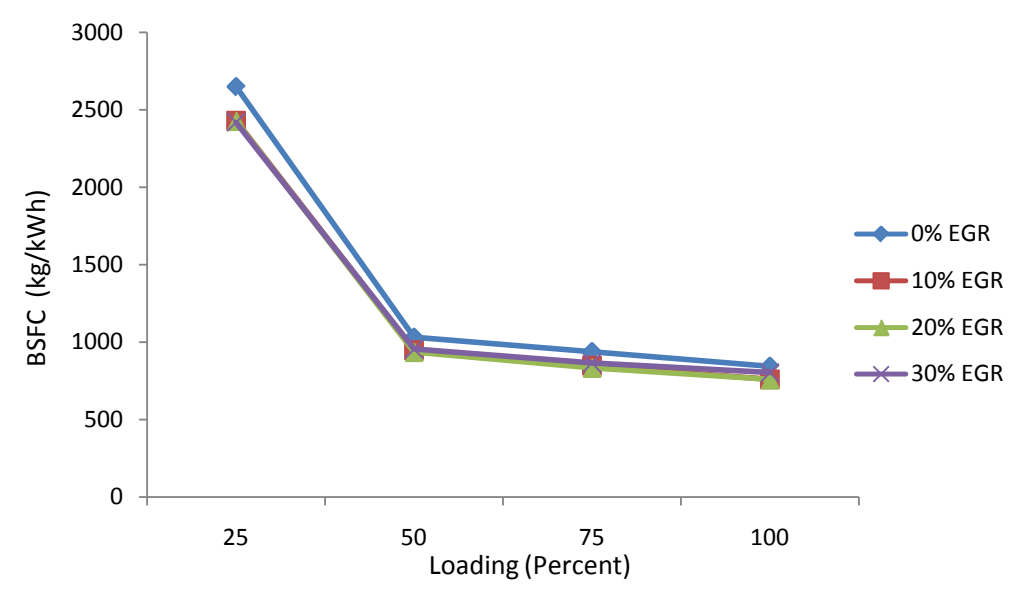

Figure 2. Variation of brake specific fuel consumption with engine load.

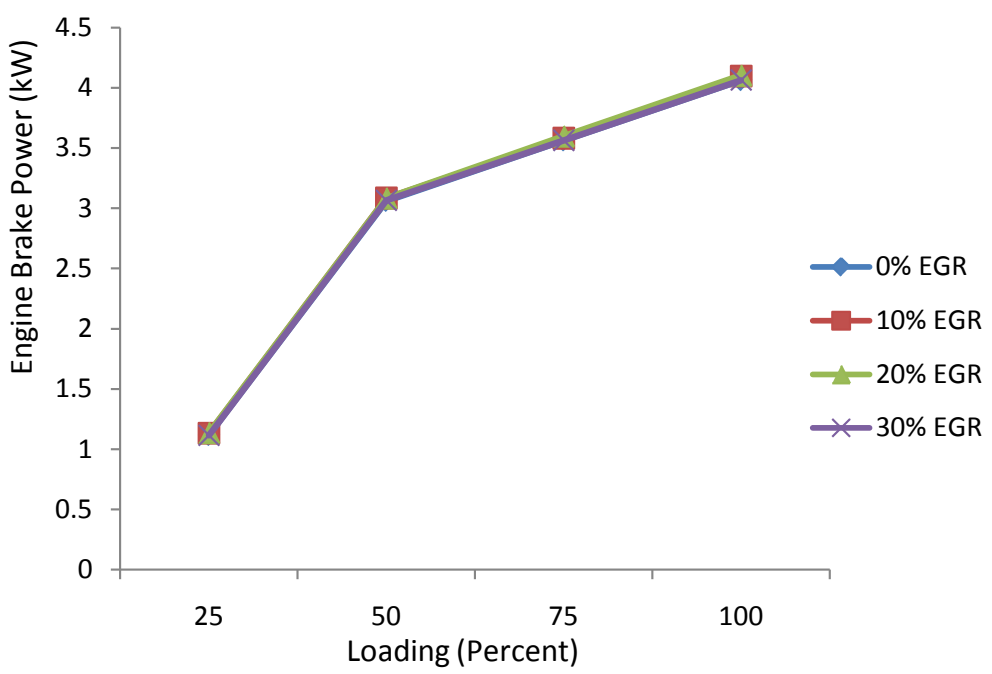

Figure 3. Brake power vs engine load.

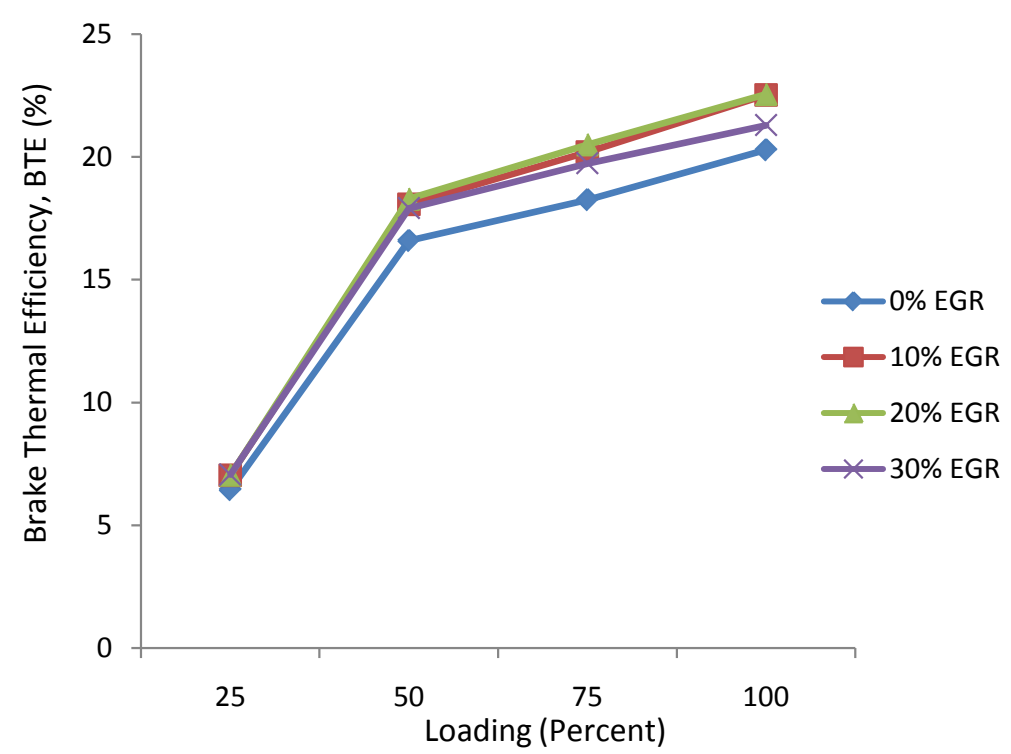

Figure 4. Brake thermal efficiency vs engine load. 


\subsubsection{Exhaust Gas Temperature (EGT)}

Figure 5 shows the variation of the exhaust gas temperature with engine load for various conditions of EGR. The exhaust gas temperature was found to increase with increase in engine load for all operating modes. This is due to the increase of total energy input at high load following higher fuel consumption. It was also found that with increase in percentage of EGR, the exhaust gas temperatures reduced. This can be attributed to the oxygen deficient operation under EGR which results in lower combustion temperatures and furthermore specific heat of exhaust gas is more than that of intake air which also contributes to the lower combustion temperatures [6]. However, the exhaust gas temperatures were found to decrease with increase in percent EGR only up to about $20 \%$ EGR, beyond which it started to increase. This shows that beyond $20 \%$ the exhaust gas starts to add heat in the combustion chamber rather than absorbing it.

\subsection{Emissions}

\subsubsection{Variation of Carbon Monoxide Emission with Load}

Figure 6 shows the variation of CO emissions with increase in percentage of EGR at $0 \%, 25 \%, 50 \%, 75 \%$ and

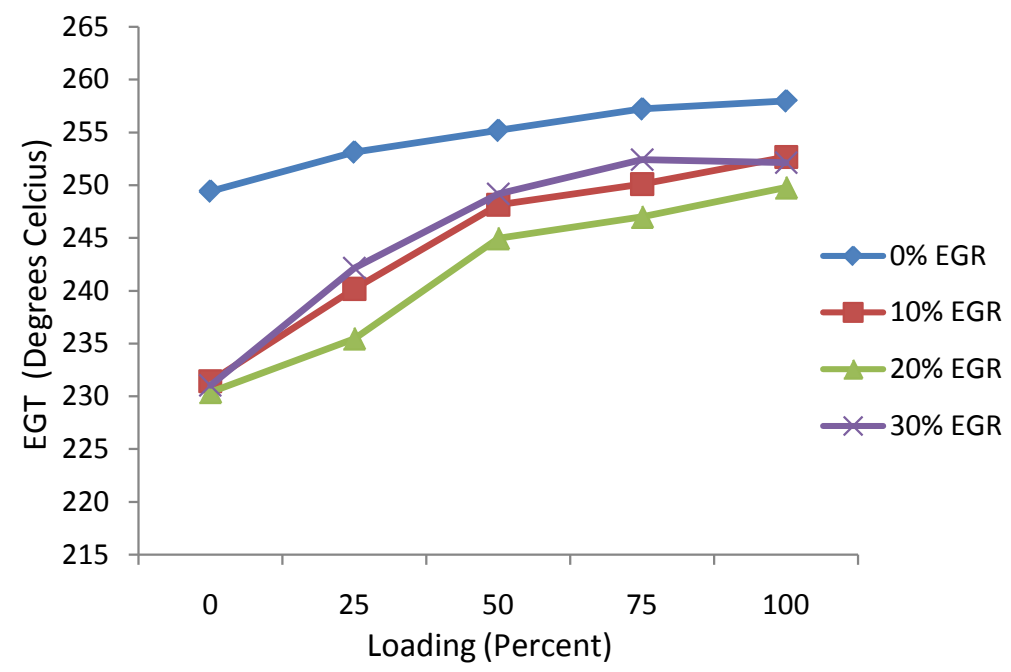

Figure 5. Exhaust gas temperature vs engine load.

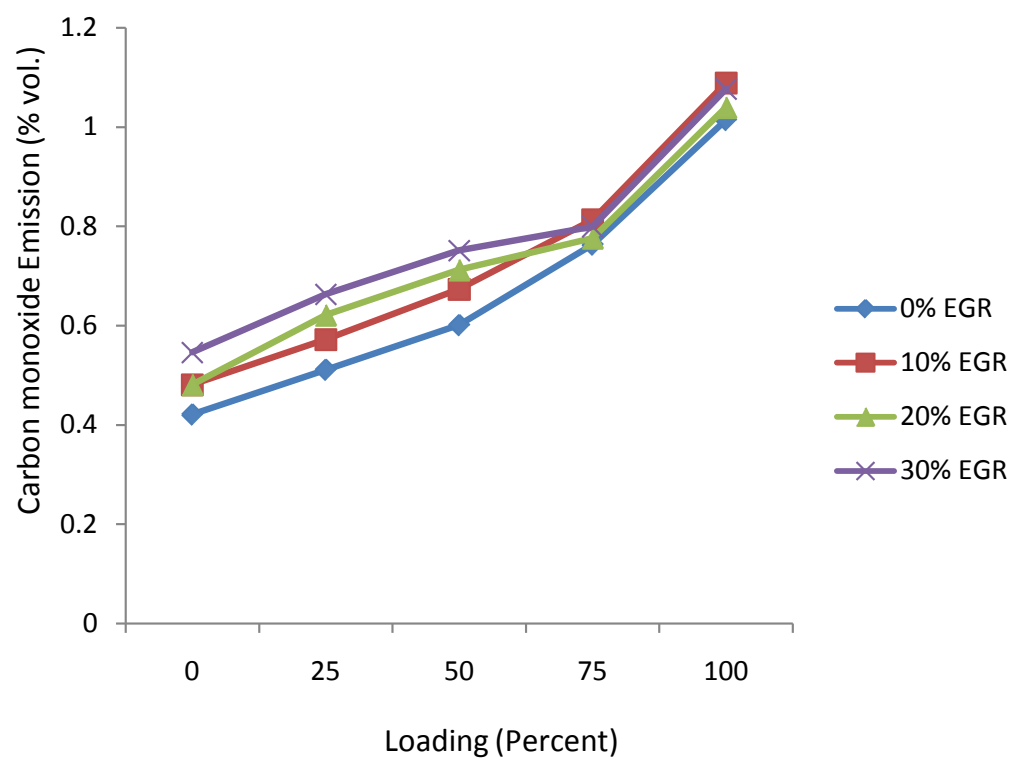

Figure 6. Carbon monoxide emission vs engine load. 
$100 \%$ loads. With increase in the percentage of EGR, CO increases; however, the effect of CO emission is found to be less at higher engine loads of $75 \%$ and $100 \%$. The emissions are found rapidly increasing with EGR up to $75 \%$ load and beyond which there is only an insignificant rise. The deficiency of oxygen with the increase in EGR percentage can be attributed to the increase in CO emission for EGR.

\subsubsection{Unburned Hydrocarbon Emission}

Figure 7 shows the variation of HC emission with increase in percentage of EGR at $0 \%, 25 \%, 50 \%, 75 \%$ and $100 \%$ loads. It can be seen from the figure that for all loading conditions, the HC emission increases with increase in EGR. The increase in $\mathrm{HC}$ emission is as a result of increase in the $\mathrm{CO}_{2}$ content of the inducted mixture instead of fresh-air. The figure also shows that unburned hydrocarbon emission decreases with increase in load for all EGR ratios. Normally dual-fuel operation exhibits higher emission of unburned hydrocarbon at light loads. At light loads the pilot quantity being small so flame cannot propagate fast and far enough to ignite the entire mixture. As the result it causes higher HC emissions but with increase in load the hydrocarbon emission decreases. As load progresses the pilot quantity increases and burns the surrounding fuel-air mixture sufficiently [7].

\subsubsection{Carbon Dioxide Emission}

From Figure 8, emission of carbon dioxide was found to increase with engine load while the same decreased slightly with EGR from 10\% to 30\% EGR. This is as a result of substitution of some of the fresh air with exhaust gas leading to decrease in $\mathrm{CO}_{2}$ which is a product of fuel combustion.

\section{Conclusions}

In this work, a single cylinder four stroke diesel engine was modified into a dual-fuel engine that used diesel as pilot fuel and biogas as the primary fuel. An experimental study was then conducted on the engine to investigate various effects of EGR on the performance and emission characteristics of a dual-fuel single cylinder four stroke DI diesel engine under various experimental conditions. The following conclusions were drawn from the analysis:

1) It was found that with increase in percent of EGR, the brake thermal efficiency increased and specific fuel consumption decreased. It was observed that with rise in \% of EGR the percentage increase in brake thermal efficiency was up to $10.3 \%$ at quarter load and up to $14.5 \%$ at full load for single fuel operation while for dual-fuel operation an increase up to $9.5 \%$ at quarter load and up to $11.2 \%$ at full load was observed. From experimental results it was found that an EGR percentage of around 20\% resulted in maximum BTE and minimum BSFC.

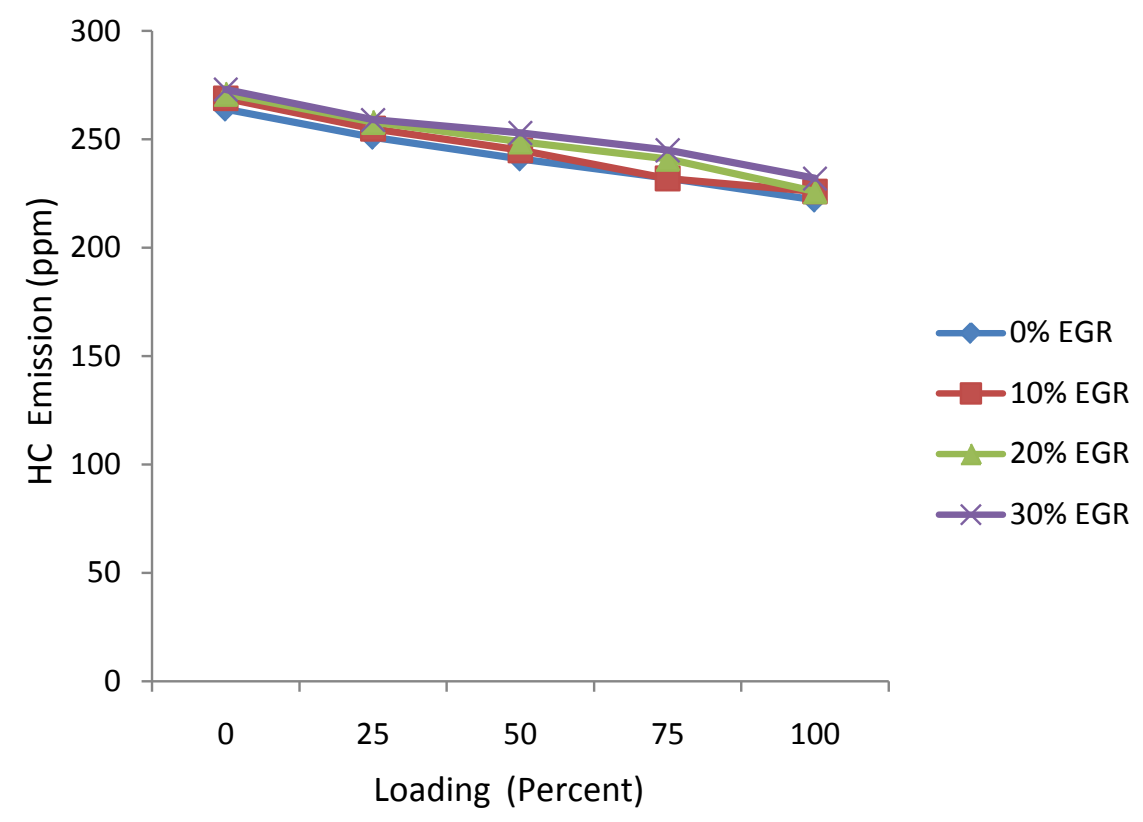

Figure 7. Unburned hydrocarbon emission vs engine load. 


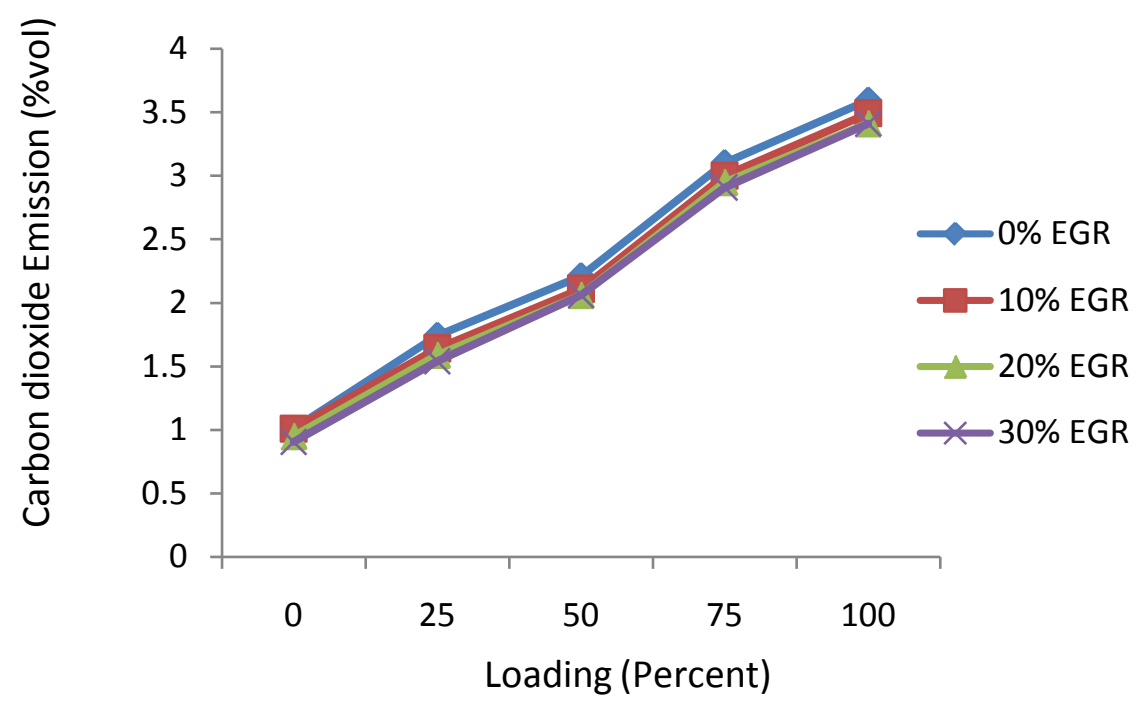

Figure 8. Carbon dioxide emission Vs Engine load.

Brake thermal efficiency increased at low EGR ratios due to the recirculation of active radicals from EGR that made the combustion process to be enhanced, so resulting in an improvement in brake thermal efficiency.

2) Results also showed that the brake power was not affected significantly by EGR.

3) Experiments were carried out using the setup to prove the efficacy of EGR as a technique for $\mathrm{NO}_{\mathrm{X}}$ reduction. It was seen that the exhaust gas temperatures reduced drastically by employing EGR. This indirectly showed the potential for reduction of $\mathrm{NO}_{\mathrm{X}}$ emission. This can be concluded from the fact that the most important reason for the formation of $\mathrm{NO}_{\mathrm{X}}$ in the combustion chamber is the high temperature of about $2000 \mathrm{~K}$ at the site of combustion. It was found that EGR reduced the exhaust gas temperature by up to $7.6 \%$ at minimum engine loading and up to $2.3 \%$ at maximum loading.

4) EGR caused a slight increase in Carbon monoxide (CO) and Hydrocarbon (HC) emissions. Increasing EGR reduced the amount of oxygen and led to incomplete combustion and therefore increased $\mathrm{CO}$ and $\mathrm{HC}$ emission due to lower combustion temperature.

\section{Acknowledgements}

The authors gratefully recognize the support from Japanese International Corporation Agency (JICA) for providing the diesel engine, electronic diesel injection pump and electronic diesel fuel injector used in this research. The authors would also like to highly appreciate Jomo Kenyatta University of Agriculture and Technology (JKUAT) for funding this research and for providing laboratory facilities for conducting experiments.

\section{References}

[1] Karim, G.A. (2003) Combustion in Gas Fueled Compression: Ignition Engines of the Dual Fuel Type. Journal of Engineering for Gas Turbines and Power, 125, 827-836. http://dx.doi.org/10.1115/1.1581894 http://gasturbinespower.asmedigitalcollection.asme.org/article.aspx?articleid=1421670

[2] Tippayawong, N., Promwungkwa, A. and Rerkkriangkrai, P. (2007) Long Term Operation of a Small Biogas/Diesel Dual-Fuel Engine for On-Farm Electricity Generation. Bio-Systems Engineering, 98, 26-32. http://dx.doi.org/10.1016/j.biosystemseng.2007.06.013 http://www.authorstream.com/Presentation/ravikantghotekar-2049447-long-term-operation-small-biogasdiesel-dual-fu el-engine-fa/

[3] Kumar, N.R., Sekhar, Y.M.C. and Adinarayana, S. (2013) Effects of Compression Ratio and EGR on Performance, Combustion and Emissions of Direct Injection Diesel Engine. International Journal of Applied Science and Engineering, 11, 41-49. http://www.cyut.edu.tw/ ijase/2013/11\%281\%29/5_023008.pdf

[4] Agrawal, A.K., Singh, S.K., Sinha, S. and Shukla, M.K. (2004) Effect of EGR on the Exhaust Gas Temperature and Exhaust Opacity in Compression Ignition Engines. Sadhana, 29, 275-284. http://www.researchgate.net/publication/257925344_Effect_of_EGR_on_the_exhaust_gas_temperature_and_exhaust 
opacity_in_compression_ignition_engines

[5] Hosseinzadeh, A., Saray, R.K. and Mahmoudi, S.M.S. (2010) Comparison of Thermal, Radical and Chemical Effects of EGR Gases Using Availability Analysis in Dual-Fuel Engines at Part Loads. Energy Conversion and Management, 51, 2321-2329. http://dx.doi.org/10.1016/j.enconman.2010.04.005 http://www.researchgate.net/publication/245160135_Comparison_of_thermal_radical_and_chemical_effects_of_EGR gases_using_availability_analysis_in_dual-fuel_engines_at_part_loads

[6] Venkateswarlu, K., Murthy, B.S.R.C. and Subbarao, V.V. (2013) The Effect of Exhaust Gas Recirculation and DiTertiary Butyl Peroxide on Diesel-Biodiesel Blends for Performance and Emission Studies. International Journal of Advanced Science and Technology, 54, 49-60. http://www.sersc.org/journals/IJAST/vol54/5.pdf

[7] Mahla, S.K., Das, L.M. and Babu, M.K.G. (2010) Effect of EGR on Performance and Emission Characteristics of Natural Gas Fueled Diesel Engine. Jordan Journal of Mechanical and Industrial Engineering, 4, 523-530. http://jjmie.hu.edu.jo/files/v4n4/JJMIE-41-09_Revised\%2812\%29/JJMIE-41-09_modified.pdf

\section{Nomenclature}

DICI-Direct Injection Compression Ignition

DI-Direct Injection

CI-Compression Ignition

SI-Spark Ignition

BTE-Brake Thermal Efficiency

BSFC-Brake Specific Fuel Consumption

EGT-Exhaust Gas Temperature

PM-Particulate Matter

$\mathrm{CO}-$ Carbon Monoxide

$\mathrm{CO}_{2}$ - Carbon Dioxide

$\mathrm{HC}$-Hydro Carbons

$\mathrm{NO}_{X}$ - Oxides of Nitrogen

LHV_-Lower Heating Value 